\title{
Health Literacy and Screening for Chronic Diseases in African Communities in the District of Columbia Metropolitan Area
}

Priscilla O. Okunji*, Ify Nwabukwu, Julia Ugorji, Nkechi Enwerem, Chidi Oriaku, Beatrice Onwudiwe, Anne Chukwu, Norah Aninta, Josephine Ezemobi, Ihuoma Ezebuihe, and Uzoamaka Okunji

Division of Nursing, Howard University, 519 Bryant Street, NW, Washington, DC 20059, USA

\begin{abstract}
According to the U.S. Census Bureau, more than two-thirds of African immigrants in the Washington metro area arrived since 1990 and more than one-third arrived just between 2000 and 2005. The health status and needs of this diverse population remain largely unexamined, unlike for many other immigrant groups. Hence, there is a clear and unmet need to determine the risks and prevalence for chronic diseases such as Hypertension, Diabetes, etc. The project capitalized on key areas of core competencies, blood pressure, blood sugar, cancer screenings and educational outreach. Culturally, relevant educational outreach, referrals and screening services were provided to participants with consented survey tool. Two phases were involved in the project. The sample size had more college graduates than other levels of education. More of the participants acknowledged that they had knowledge of healthy blood pressure and knew what to do in case of heart attack. However, it is important to note that only $41 \%$ of the participants had knowledge of fruits and vegetable, $24 \%$ of sodium and $35 \%$ of cholesterol content of food, the rationale for our educational outreach, screening and referral initiation. The authors are calling for more engagement in outreach education for sustainability, especially on relationship between lifestyle (diet, smoking, etc) and heart disease, in order to build capacity and prevent the most deadly diseases in the African immigrant community.
\end{abstract}

\section{Introduction}

African immigrants represent one of the fastest growing groups of immigrants to the United States. Over the past 50 years, African migration to the US has increased 40 -fold and there are now approximately 1.5 million African-born persons resident in the US; $10 \%$ of whom live in the Washington DC area [1]. Health status and needs of this diverse population remain largely unexamined, unlike for many other immigrant groups. Africans represent the most rapidly expanding immigrant groups with the following concentration regions--Washington D.C., New York City, Minneapolis-St. Paul and Atlanta. The countries of origin most represented in the District are: Ethiopia $17 \%$, Nigeria $12 \%$, Ghana $10 \%$, Egypt $4 \%$, Cameroon $9 \%$, Liberia $4 \%$, Somalia $3 \%$, Guinea $3 \%$, Sudan $2 \%$, and Eritrea $2 \%$ [2]. Studies have revealed that more than two-thirds of African immigrants in the Washington metro area arrived since 1990 and more than one-third arrived just between 2000 and 2005 [3]. About $84 \%$ of this population is of working age (between 18-64 years old) [4].

As the number and diversity of Africans in the U.S. increases, there is a growing need to assess their health care needs and practices. Most public health reports involving African immigrants have focused on infectious diseases, including HIV and TB. There is a clear and unmet need to determine the risks and prevalence for chronic diseases (Hypertension, Diabetes, etc) [4]. With the increase of childhood obesity, of which African born children in this country are inclusive, at least one hundred and eighty African immigrant residents' of Washington DC were screened for diabetes and hypertension from age 18 and older.

Africans, like other racial and ethnic minorities, face a myriad of systemic and other deep-rooted barriers to accessing screening and follow-up care. For example, language barriers adversely impact health care information exchange; lack of awareness of family medical history is a risk factor; cultural beliefs that consider disease as a punishment or a curse; the tendency to seek medical attention for a cure rather than prevention - often seen as a "western luxury"; and financial hardships and lack of accessibility to health care providers are prevalent barriers for the African immigrant community. Other barriers include limited research in the African community, lack of insurance due to the part-time jobs that most African immigrant do, most African immigrants are not informed of the medical opportunities at their disposal, most providers have limited knowledge of cultures and beliefs of the African immigrant people, lack of collective action to address health disparities within the African immigrant community, lack of participation in clinical trials and yet the results of these trials are important in directing treatment and care to communities.

In the U.S., diabetes affects twenty six million people, seven million of whom are undiagnosed [5]. According to the Center for Disease Control, between 1980 through 2011 the number of individuals with diabetes has tripled from 5.6 million to 20.9 million. The actual national cost is estimated to be over $\$ 174$ billion when other burdens such as the social cost of intangibles like pain and suffering, care provided by non-paid caregivers, excess medical costs associated with undiagnosed diabetes, and diabetes-attributed costs for health care expenditures categories are included [6]. The diabetes prevalence pattern is changing. Previously, type 2 diabetes (T2D) was referred to as

"Corresponding Author: Dr. Priscilla O. Okunji, Division of Nursing, Howard University, 519 Bryant Street, NW, Washington, DC 20059, USA; E-mail: priscilla.okunji@howard.edu

Citation: Okunji PO, Nwabukwu I, Ugorji J, Enwerem N, Oriaku C, et al. (2017) Health Literacy and Screening for Chronic Diseases in African Communities in the District of Columbia Metropolitan Area. Int J Nurs Clin Pract 4: 241. doi: https://doi.org/10.15344/2394-4978/2017/241

Copyright: (c) 2017 Okunji et al. This is an open-access article distributed under the terms of the Creative Commons Attribution License, which permits unrestricted use, distribution, and reproduction in any medium, provided the original author and source are credited. 
Citation: Okunji PO, Nwabukwu I, Ugorji J, Enwerem N, Oriaku C, et al. (2017) Health Literacy and Screening for Chronic Diseases in African Communities in the District of Columbia Metropolitan Area. Int J Nurs Clin Pract 4: 241. doi: https://doi.org/10.15344/2394-4978/2017/241

Page 2 of 3

"a disease of affluence," but it is now increasingly common among the poor; T2D is also more common among under represented minorities [7]. In the United States, it was estimated that diabetes accounted for $12 \%$ of health expenditures in 2010 , or at least $\$ 376$ billion a figure expected to reach $\$ 490$ billion in 2030 [8].

Diabetes is linked to an increased prevalence of hypertension, a critical comorbidity for heart attack. Many studies have reported that diagnosis of both diabetes and heart attack results in an increased mortality risk, beyond that of having diabetes alone $[9,10]$. Heart attack, a complication of type 2 diabetes (T2D) is an important variable of morbidity and mortality worldwide [11]. Diabetes is common in heart attack patients and is independently associated with increased risk for cardiovascular morbidity [12] and mortality [13,14]. The risks of getting heart disease and related disorders are even higher for Africans. The good news is, Africans can improve their odds of preventing and beating these diseases by understanding the risks and taking simple steps to address them; this could be achieved through preventive measures as in health literacy, screening and referral. Hence, more research is needed in this population, particularly involving rates of heart disease, diabetes among African immigrants. Large urban hospitals may be in a good position to conduct studies on these questions but most immigrants may not have insurance to be admitted in such hospitals.

Studies have shown that interventions that focus not only on increasing knowledge, but also on surmounting financial and logistical barriers to accessing screening and follow-up care will be the most successful [15]. African immigrants in Washington DC will be well-served by specifically tailored, culturally appropriate community outreach and patient navigation strategies that can address real and perceived barriers to hypertension, diabetes and breast cancer screening and follow-up [16].

\section{Method}

The project capitalized on key areas of core competencies, blood pressure, blood sugar, screenings and educational outreach. Culturally relevant educational outreach, referrals and screening services were provided to participants consented to the screening and the survey tool. Event venues included places trusted and frequented by African immigrant, including the worship areas, community centers, and community health fairs in the African community. African immigrants, especially from Sub Saharan African region (Figure 1) in the wider DC area often cross geographic boundaries to attend African immigrant-related events, some of the participants who attended our sessions came from the surrounding Maryland/Virginia area, especially Montgomery and Prince George's County. Two phases were involved in the project $[17,18]$.

\section{Results}

The analysis of the first phase of the data showed that more males (63\%) than their females (27\%) counterparts participated with age range from 15-70 years and blood pressure measures were from 97/73$167 / 103$ (a participant who was on medication and referred). The sample size had more college graduates than other levels of education. More of the participants acknowledged that they had knowledge of healthy blood pressure and knew what to do in case of heart attack. However, it is important to note that only $41 \%$ of the participants had knowledge of fruits and vegetable, $24 \%$ of sodium and $35 \%$ of cholesterol content of food, the rationale for our educational outreach, screening and referral initiation. On the other hand, the second phase of data analysis showed that more females attended the outreach event than their female counterparts with age range between $18-80$ years. The blood sugar ranged from 75 to $>400 \mathrm{mg} / \mathrm{dl}$ (with some referrals).

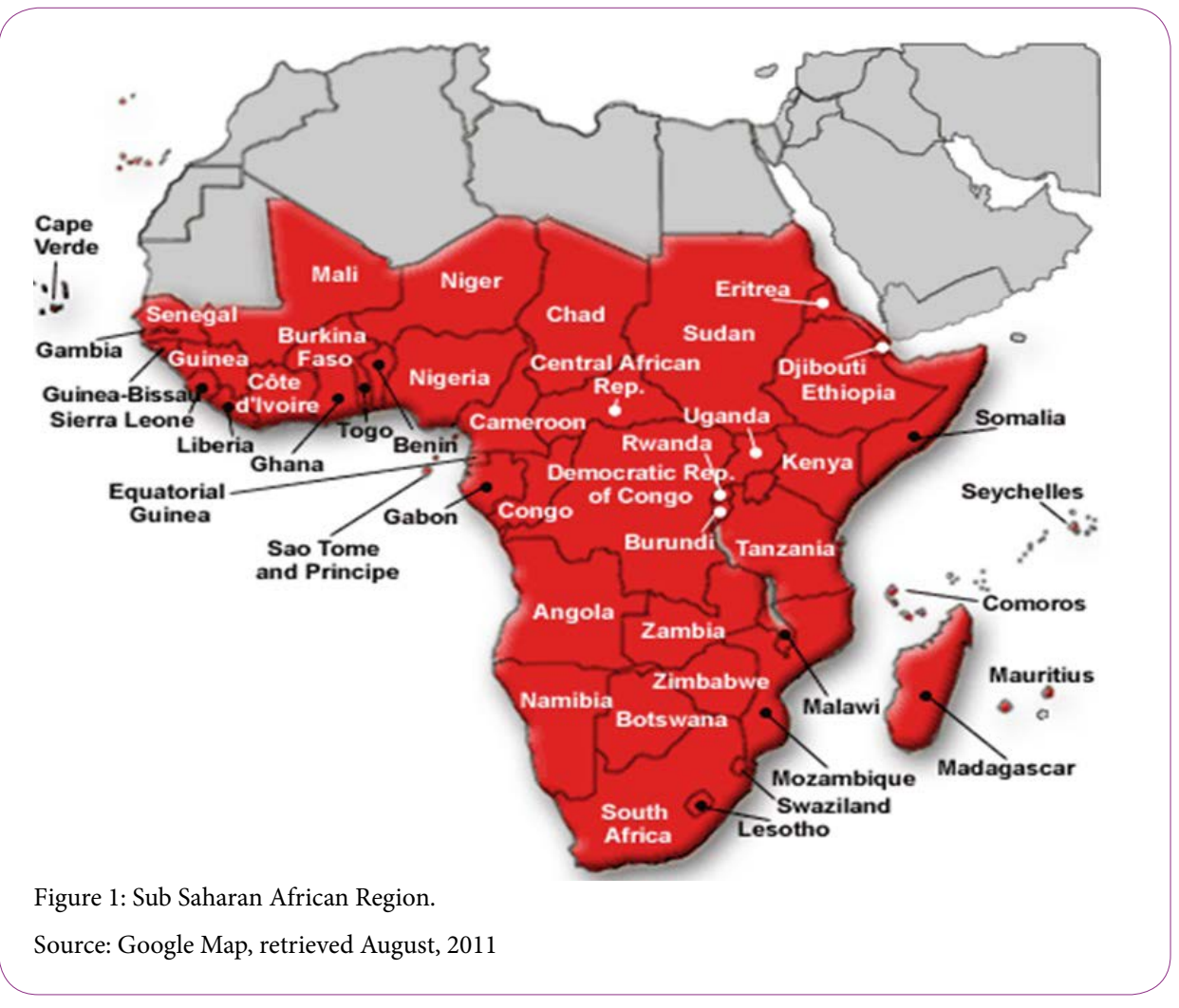

Int J Nurs Clin Pract 
Citation: Okunji PO, Nwabukwu I, Ugorji J, Enwerem N, Oriaku C, et al. (2017) Health Literacy and Screening for Chronic Diseases in African Communities in the District of Columbia Metropolitan Area. Int J Nurs Clin Pract 4: 241. doi: https://doi.org/10.15344/2394-4978/2017/241

Page 3 of 3

Few finger stick measures were found to be higher than usual as some participants had already eaten prior to the screening, hence post prandial effect was noted.

\section{Discussion \& Conclusion}

Interventions that are not culturally and linguistically appropriate are unlikely to succeed when implementing preventive measures in African immigrant community. National Association of Nigerian Nurses in North America (NANNNA) and African Women Cancer Awareness Association (AWCAA) projects' successes are based in no small part on its attention to cultural and linguistic competency in all of its services. Our associations were founded by African immigrant women and have historically operated with a cadre of staff and volunteers comprised mainly of African immigrant men and women, many of whom have had personal or family experiences with these chronic diseases. Professional nurse members, volunteers and staff live, work and worship within the Washington DC area and are members of the communities this project serves. The staff and volunteers represent many African countries and together speak many major languages and multiple local dialects. Health screening and health literacy, will likely contribute to community-based data concerning chronic diseases among African immigrants. Related to prevalence is the issue of screening for chronic disease. Are African immigrants receiving recommended health screenings at rates similar to other immigrant groups? Are educational campaigns about these screenings being targeted to high density areas of African immigrants such as places of employment (taxi waiting areas), religious institutions, African shops, community based organizations, and private residences?

The authors are calling for more research and engagements in outreach education for sustainability, especially on relationship between lifestyle (diet, smoking, etc) and chronic diseases, in order to build capacity and prevent the most deadly diseases in the African immigrant community.

\section{Competing Interests}

The authors declare that they have no competing interests.

\section{References}

1. McCabe K (2011) African immigrants in the United States. Migration Policy Institute.

2. American Community Survey data, 2012

3. U.S. Census Bureau. U.S. census 2000

4. Venters H, Gany F (2011) African Immigrant Health. J Immigrant Minority Health13: 333-344

5. Centers for Disease Control and Prevention (2011) National diabetes fact sheet: national estimates and general information on diabetes and prediabetes in the United States; 2011. Atlanta, GA: U.S. Department of Health and Human Services, Centers for Disease Control and Prevention.

6. Kamaruddin MS, Quinton R, Leech RN (2008) Standards of Medical Care in Diabetes 31, Supplement 1: S12-S54.

7. Hu FB (2011) Globalization of Diabetes: The role of diet, lifestyle, and genes. Diabetes Care 34: 1249-1257.

8. Zhang P, Zhang X, Brown J, Vistisen D, Sicree R, et al. (2010) Globa healthcare expenditure on diabetes for 2010 and 2030. Diabetes Res Clin Pract 87: 293-301.

9. Bot M, Pouwer F, Zuidersma M, van Melle JP, de Jonge P (2012) Association of coexisting diabetes and depression with mortality after
10. Okunji PO, Gomez F (2014) Effects of Patients and Hospital Characteristics on Myocardial Infarction Mortality: Health Disparity Outcomes. Association of Black Nursing Faculty Journal 25: 13-18.

11. White HD, Chew DP (2008) Acute myocardial infarction. Lancet 372: 570584.

12. Van Melle JP, Bot M, de Jonge P, de Boer RA, van Veldhuisen DJ, et al. (2010) Diabetes, glycemic control, and new- onset heart failure in patients with stable coronary artery disease: data from the Heart and Soul Study. Diabetes Care 33: 2084-2089.

13. Donahoe SM, Stewart GC, McCabe CH, Mohanavelu S, Murphy SA, et al. (2007) Diabetes and mortality following acute coronary syndromes. JAMA 298:765-775

14. Koek HL, Soedamah-Muthu SS, Kardaun JW, Gevers E, de Bruin A, et al. (2007) Short- and long-term mortality after acute myocardial infarction: comparison of patients with and without diabetes mellitus. Eur J Epidemiol 22: 883-888.

15. Masi CM, Blackman DJ, Peek ME (2007) Interventions to enhance breast cancer screening, diagnosis, and treatment among racial and ethnic minority women. Med Care Res Rev 64: 195S-242S.

16. Sheppard VB, Christopher J, Nwabukwu I (2010) Breaking the silence barrier: Opportunities to address breast cancer in African-born women. $J$ Natl Black Nurses Assoc 102: 461-468.

17. Gibney KB, Mihrshahi S, Torresi J, Marshall C, Leder K, et al. (2009) The profile of health problems in African immigrants attending an infectious disease unit in Melbourne, Australia. Am J Trop Med Hyg 80: 805-811.

18. Okunji PO, Afghani A, Gomez F (2012) Exploring the Disparities in Healthcare Outcomes of Inpatient Diabetic Myocardial Infarction Transfers in Non Federal Hospitals. J Natl Black Nurses Assoc 23: 29 -33. 